\title{
A Sustainable Environment for whom?
}

\author{
Fernando Ferreira Carneiro ${ }^{1}$, Vanira Matos Pessoa ${ }^{1}$
}

The recognition of the importance of the environmental issue in the social determination of health is related to the evolution of the paradigms concerning health since the times of the treaty "Of the airs, waters and places", produced by Hippocrates, going through the studies on the precariousness of the life situation of the working class in the period of the Industrial Revolution, up to the complex web of contexts and risks associated with the globalized development model in contemporaneity.

The changes in the environment, associated with air pollution and water and soil contamination, have been reaching an ever-increasing amount of people. The exposure to contaminants and pollutants in society does not happen in an equal way. The poorest population, in general children, elderly, workers and traditional populations, for example, have increasingly been receiving a burden of this contamination/ pollution, which is associated with individual and biological dimensions, as well as to work environments, shortage of sewage disposal, inappropriate dwellings, lack of health services, gentrification, desertification, deforestation, intensive use of agrochemicals in food production, etc.

Thus, considering this context in the analyses of the health situation and relate them with the health profile of the Brazilian population becomes increasingly necessary, mainly for the public policies. According to the historical construction, three groups of illnesses are prevalent within the current health framework, all shaped by different social and environmental contexts. The first one reveals, predominantly, cardiovascular and neoplastic diseases, whose increasing tendency walks hand in hand with the population aging. This situation becomes possible as these morbid expressions are considered as the effect of genetic, life and work conditions experienced by these populations, particularly those exposed to certain environmental pollutants. The second group is composed of infectious and parasitic diseases, which are markedly determined by social and environmental conditions. The so-called external causes make up the third scenario, including accidents and forms of violence, which constitute social and environmental events that produce traumas, injuries and harms, whose increase have been highlighted.

One concept that helps us to understand these differences is that of Environmental Injustice, which derives from the ascertainment that the growing shortage of natural resources and the destabilization of ecosystems affect in an unequal way and, often, unrighteous, the different social groups or geographic areas.

Brazil has adopted a development model focused on the exploitation of natural resources, which consists in a process of economic reprimarization. The deployment of enterprises makes use of economic blackmail, in terms of job creation, with the aim of inserting them into geographic areas occasionally unsustainable from the environmental viewpoint. Therefore, there is a need to produce a type of knowledge that is allied to these vulnerable groups, besides a strong mobilization focused on universal rights, in order to ensure that the health of this population is not endangered by this development model.

${ }^{1}$ Fundação Oswaldo Cruz. Fortaleza, CE, Brazil.

Corresponding author: Fernando Ferreira Carneiro

Av. Santos Dumont, 5753 - 1303 - CEP: 60180-900. Fortaleza, CE, Brazil. E-mail: fernando.carneiro@fiocruz.br 